Svetlana Velimirac

Univerzitet u Beogradu

Filološki fakultet
37.016:811]:004

https://doi.org/10.18485/filkult.2016.1.ch16

\title{
DIGITALNO DOBA I USAVRŠAVANJE NASTAVNIKA STRANOG JEZIKA
}

\begin{abstract}
Sažetak
Usavršavanje nastavnika stranih jezika u digitalnoj eri podrazumeva prilagođavanje vremenu u kome nastavnik realizuje svoje aktivnosti, samim tim i tehnologijama koje ga okružuju, a koje su postale sastavni deo radne svakodnevice. U ovom radu predstavljen je primer usavršavanja nastavnika engleskog jezika putem otvorenog masovnog onlajn kursa (MOOC) pod nazivom Paths to Success in English Language Teaching - Shaping the Way We Teach English. Prednosti i nedostaci ovakvog vida usavršavanja, kao i potvrda formiranja delatne zajednice pri aktivnom učestvovanju nastavnika u radu otvorenog masovnog onlajn kursa okosnica su ovog rada. Tehnologija je sastavni deo procesa učenja na daljinu, čime se, pored osnovne namene određenog kursa, podrazumeva napredak i razvoj nastavnika jezika i iz informaciono-komunikacione oblasti, što je danas podrazumevana veština za svakog savremenog nastavnika. Razmena iskustava, ideja $i$ povezivanje sa kolegama sa različitih meridijana $i$ iz različitih društvenih $i$ obrazovnih sredina dodatni su podsticaj za prihvatanje ovog globalnog trenda u usavršavanju znanja i veština nastavnika stranih jezika i u našoj sredini.
\end{abstract}

Ključne reči: E-učenje, delatne zajednice, nastavnici, usavršavanje, MOOK

\section{Uvod}

Uvođenje savremenih tehnologija u proces nastave nije nova pojava, prosvetni radnici zainteresovani za podizanje kvaliteta svog rada oduvek su se trudili da tehnološke novine upotrebe kako bi se nastava učenicima i studentima približila i olakšala. Sa druge strane, i nastavnici su u neprekidnom toku učenja i usavršavanja svojih znanja i veština. Svesni ograničenja koje nam nameće tempo života u 21. veku, kao što su nedovoljno slo- 
bodnog vremena, limitirani resursi ili materijalne mogućnosti nastavnika, mnoge obrazovne ustanove u svetu razvile su programe učenja na daljinu. Ovakvi programi razvijaju se paralelno sa napretkom informaciono-komunikacione delatnosti i pokrivaju brojne oblasti, sa ponudom od uvodnih i opšteobrazovnih kurseva do usko specijalizovanih. Jedan deo njih namenjen je i razvoju veština nastavnika.

Najuočljivija prednost ovakvog tipa usavršavanja je ta što su polaznici kursa i predavači fizički razdvojeni, ponekad i hiljadama kilometara i u različitim vremenskim zonama, a da to ne sprečava uspešnu realizaciju kursa. Drugo, tehnologija je sastavni deo procesa učenja u ovakvoj postavci, čime se podrazumeva napredak i razvoj polaznika kursa i iz informaciono-komunikacione oblasti. „Učenje na daljinu“ (eng. e-learning) kreira „dinamičnu sredinu koja zahteva da se polaznici angažuju i aktivno učestvuju u sopstvenom učenju" (Sivakumar 154).

Jednu od podvrsta učenja na daljinu predstavljaju masovni otvoreni onlajn kursevi (eng. MOOCs - Massive Open Online Courses). Ovi kursevi podstiču onlajn učestvovanje neograničenog broja polaznika u okviru višenedeljnog rada sopstvenim tempom i u onim terminima koje polaznik sam izdvoji za kurs. Cilj ovih kurseva je razvijanje kompetencija polaznika u određenoj oblasti, ali i objedinjavanje delatne zajednice ${ }^{1}$ - npr. nastavnika stranog jezika, koji u okviru kursa dele zajednička iskustva i uče jedni od drugih:

Kao što su Spender, Braun, Venger, Baumrd i drugi istakli, znanje ima društvenu dimenziju - može biti stvoreno i održavano kolektivno. Ljudi koji imaju isto radno iskustvo, probleme sa planovima i imaju slične mogućnosti za učenje formiraju zajednicu prakse (Lave i Venger 1991). Venger (2000) definiše zajednicu prakse kao društveni sistem učenja, ujedinjen u istom preduzeću, zajednički prepoznaje norme i kompentenciju, sa istim jezikom, rutinom i pričama... Članovi zajednice prakse nastupaju kao izvor jedni drugima, „razmenjujući informacije, dele nove trikove i ideje". (Venger, 1998, str. 47) ...Zajednica prakse prema tome, predstavlja oazu u kojoj procesi znanja funkcionišu prirodno (Marković 72-73).

1 Delatna zajednica predstavlja grupu ljudi koja se okuplja oko zajedničkog angažovanja na određenom poduhvatu. (Eckert, \& McConnell-Ginet 1992:464; cit. u: Holmes \& Meyerhoff 1999: 174) (Filipović 132). 


\section{Masovni otvoreni onlajn kursevi}

Prvi masovni otvoreni onlajn kursevi zaživeli su 2008. godine, nudeći studentima besplatne materijale za učenje, mogućnost razmene mišljenja između studenata i profesora na onlajn forumima i blogovima, a potom su se razvile i platforme koje olakšavaju pregled materijala i onlajn praćenje (Liyanagunawardena 203). Veliki broj prestižnih obrazovnih ustanova širom sveta kao što su univerzitet Stenford, MIT, Harvard, Oksford itd. ubrzo su prihvatile ovaj koncept unapređivanja i deljenja znanja, tako da su kursevi postali dostupni širokoj populaciji bez novčane naknade. Sve veći broj kurseva nalazi se u ponudi i njihova popularnost neprekidno raste. Vremenom se pojedine ustanove udružuju i stvaraju nove namenski dizajnirane platforme, odnosno sisteme za upravljanje učenjem (eng. Learning Management Systems) koji se međusobno razlikuju. Ovi sistemi mogu da budu komercijalni (kao što su BlackBoard, Desire2Learn) ili otvorenog tipa (Moodle, Sakai itd.). Pojedine platforme nude kurseve sa opcijom prikazivanja titlova na drugim jezicima, kako bi se privukli polaznici koji ne govore ili nemaju dovoljan nivo znanja engleskog jezika; na neke od kurseva polaznici mogu da se prijave putem Fejsbuka ili Tvitera; neki kursevi propisuju rokove, dok drugi omogućavaju savladavanje celokupnog gradiva sopstvenim tempom; pojedini kursevi nude uz novčanu naknadu i dodatni rad sertifikate koji su još konkurentniji na tržištu rada. Takođe, razlikuje se i vreme predviđeno za prijavljivanje na kurseve; dok se neki „oglašavaju“ mesecima unapred i dopuštaju prijavljivanje i nakon početka kursa, drugi imaju kratak period najave i striktno zacrtano vreme prijave za kurs.

Ono što je zajedničko za sve masovne otvorene onlajn kurseve je da su jasno naznačeni jezik i tema kursa, njegovo trajanje, period u kom će se kurs realizovati, naziv institucije koja kurs organizuje i imena predavača, broj radnih sati za ispunjavanje predviđenih nedeljnih obaveza (za prosečnog polaznika), da li je neophodno određeno stručno predznanje i koji resursi su potrebni za pohađanje kursa (obično su to kompjuter i internet konekcija). Kako su u najvećem broju slučajeva kursevi predviđeni za govornike engleskog jezika i digitalno pismene ${ }^{2}$, ova dva uslova is-

2 Pogledati odeljak: IKT i koncepti pismenosti u dokumentu Smernice za unapređivanje uloge informaciono-komunikacionih tehnologija u obrazovanju, Nacionalni prosvetni savet Republike Srbije, Beograd, 2013. god. 
tovremeno mogu da predstavljaju i ograničenja u mogućnosti pohađanja ovakvih kurseva i unapređenju ličnih i stručnih kompetencija. Savremeno društvo zahteva profesionalni razvoj zaposlenih u obrazovanju, pa tako i informatičku pismenost uz sve ostale oblike pismenosti. Standardi kompetencija za profesiju nastavnika i njihovog profesionalnog razvoja određuju koje kompetencije nastavnici treba da imaju da bi uspešno obavljali svoju profesiju, a poznavanje informaciono-komunikacionih tehnologija i njihova upotreba sve više će dobijati na značaju i postati podrazumevana veština.

\section{Primer MOOK-a za nastavnike engleskog kao stranog jezika}

Kada poredimo tradicionalne sa savremenim pretpostavkama o obrazovanju Malkoma Nolsa, izdvaja se tvrdnja o nastavniku iz ove dve perspektive. Kao tradicionalnu tvrdnju, Nols navodi: „Osoba je u potpunosti spremna za obavljanje profesije do kraja svog života po okončanju formalne profesionalne obuke" (Wallace 40). Nasuprot ovog stava o nastavničkoj delatnosti, savremena tvrdnja bila bi sledeća: „Kako se tehnologija i društveni uslovi brzo menjaju, osoba postaje zastarela u profesionalnom smislu ukoliko se ne angažuje celoživotnim programom profesionalnog razvoja" (Wallace 40). Pored formalnih vidova obrazovanja za nastavnički poziv, kontinuirano usavršavanje je imerativ za nastavnike koji žele da budu savremeni, konkurentni i aktivni članovi obrazovne zajednice te stoga samostalno traže nove izvore znanja, alate i instrumente kojima bi unapredili nastavnu praksu.

Jedan od mnogobrojnih je i pohađanje masovnih otvorenih onlajn kurseva. Kao što je prethodno pomenuto, ovakvi kursevi su za nastavnike pogodni jer ne zahtevaju fizičko prisustvo u određeno vreme na određenom mestu već se održavaju u onlajn prostoru i vremenu, tako da nastavnici mogu da se posvete usavršavanju kada procene da imaju vremena koje će da izdvoje za tu namenu. Sledeća prednost je ta što organizatori MOOK-a ne zahtevaju finansijsku nadoknadu za sam kurs, već su dovoljni, ali i neophodni resursi kompjuter i internet konekcija. Prijavljivanje i pohađanje kursa vrši se na dobrovoljnoj bazi. S obzirom da se celokupna komunikacija kao i deljenje materijala vrši onlajn, MOOK doprinosi i očuvanju prirodnih resursa. Pohađanjem ovih kurseva povezuju se nastavnici koji se bave istim 
ili sličnim nastavnim sadržajima i zaključno, „....znanje može biti razmenjivano između različitih konteksta pod uslovom da primalac može da ga shvati i da ga poveže sa svojim specifičnim kontekstom" (Marković 85), odnosno, ovakvi kursevi pružaju mogućnost da stečeno znanje nastavnici primene u sopstvenom kontekstu - u svojoj učionici.

Među ponudom kurseva namenjenih nastavnicima engleskog kao stranog jezika, za ovaj rad odabran je MOOC Paths to Success in English Language Teaching - Shaping the Way We Teach English (1 and 2) ${ }^{3}$, sa portala neprofitabilne obrazovne organizacije Coursera.

Ovaj masovni otvoreni onlajn kurs pripada kategoriji Obrazovanja i Profesionalnog usavršavanja nastavnika. Preporučen je nastavnicima koji su već stekli određeno iskustvo u nastavi, ali rad u struci nije neophodan uslov da bi se kurs savladao sa uspehom. Zamišljen je i predstavljen kao kolaborativni kurs, sa naglaskom na tome da se napredak ostvaruje tako što se ideje predstavljaju i dele sa ostalim polaznicima kursa. Time je uloga koju polaznik kursa zauzima dvojaka: istovremeno, on plasira svoje znanje, ali je i u prilici da uči od drugih. Davenport i Pruzak (Wallace 110) govore o ekonomskom modelu deljenja znanja u kome se preklapaju odvojene i promenljive uloge tzv. kupaca znanja, prodavaca znanja i brokera znanja. Ovakav model je, izuzev finansijske podloge, prisutan i u MOOK-u: nastavnik preuzima i stiče znanje, deli ga sa drugima i plasira ga tokom kursa, a zatim i izvan njega. Drugi autori nude model koji je više altruistički, po kome se znanje deli zarad opšteg dobra (Wallace 110). Koji god model da prihvatamo kao referentan, svakako da je zadatak nastavnika - polaznika MOOK-a višeslojan: nastavnik uči, ali naučeno dalje prosleđuje i deli kako sa svojim kolegama, tako i primenjujući ga unutar ustanove u kojoj je zaposlen, sa učenicima ili studentima i u drugim kontekstima.

O samoj primeni naučenog, autori kursa nude set pitanja koja pomažu da se sagleda svrha pohađanja kursa u ličnom kontekstu:

Kako ću naučeno da primenim u sopstvenoj učionici?

Kako ću naučeno da prilagodim mojim studentima i njihovoj kulturi? Kako ću naučeno da prilagodim različitim nastavnim materijalima i ciljevima?

Koji resursi su mi potrebni za pohađanje ovog MOOK-a?

3 https://www.coursera.org/course/shaping2paths [Pristupljeno sajtu novembar-decembar 2015.] 
Na poslednje pitanje, uvodne informacije MOOK-a daju odgovor: potrebna je pouzdana internet konekcija, kompjuter ili drugi mobilni uređaj (tablet, smartfon) na kome mogu da se reprodukuju audio i video fajlovi, i neophodno je znanje engleskog jezika u dovoljnoj meri da bi se razumeo pročitani ili izgovoreni sadržaj tokom kursa, kao i da bi se učestvovalo u pisanim diskusijama.

Onlajn MOOC Paths to Success in English Language Teaching Shaping the Way We Teach English 1 and 2, realizovan je kroz saradnju i organizaciju Univerziteta u Oregonu, Sjedinjene Američke Države i američkog Stejt dipartmenta. Predavači/voditelji kursa su dr Deborah Healey, Jeff Magoto i dr Elizabeth Hanson-Smith, svo troje sa Univerziteta u Oregonu, Sjedinjene Američke Države. U ponudi su dva kursa u trajanju od po pet nedelja. Za kurseve polaznici treba blagovremeno da se prijave putem registracije. Mogu da se prijave za samo jedan ili drugi MOOK, koji su međusobno nezavisni, ili za oba. Tokom kursa, polaznici su u prilici da savladaju najvažnije aspekte podučavanja engleskog jezika kao stranog ili drugog jezika. Nastavnicima koji već imaju iskustva u radu, ovaj MOOK pomaže da obnove i osveže svoja znanja, metode i pristupe u nastavi, kao i da razmene ideje i iskustva sa nastavnicima širom sveta. Kurs može da služi i kao dopuna TEFL/TESOL metodama podučavanja engleskog kao stranog jezika.

Cilj kursa je profesionalni i stručni razvoj nastavnika, što vodi ka kvalitetnijoj nastavi i boljim rezultatima u radu sa učenicima/studentima. Ovaj MOOK predstavlja kurs obuke za nastavnike engleskog jezika, ali nije preskriptivne prirode. Sastavljen je iz materijala koji obuhvataju video segmente i stručno-naučne članke, kao i niza realnih zadataka iz nastavničke prakse koji se postavljaju pred polaznike, za čije rešavanje je neophodna saradnja i povezivanje sa ostalim polaznicima kursa.

\section{Organizacija MOOK-a}

Zadaci koje polaznici kursa ispunjavaju tokom trajanja svih pet nedelja zahtevaju od nastavnika angažovanje u raznovrsnim aktivnostima. Situacija u koju se nastavnik postavlja veoma je slična stvarnim ulogama koje on treba da savlada tokom rada u struci, tj. nastavi. Ti zadaci obuhvataju: 
- Aktivno gledanje video materijala. Tokom gledanja video segmenata, na ekranu se pojavljuju pitanja koja olakšavaju razumevanje posmatranog materijala i kojima se proverava i potvrđuje usvajanje predstavljenih pojmova/sadržaja. Video materijali su najčešće snimci stvarnih situacija iz učionica sa časova nastave engleskog jezika.

- Rešavanje kvizova, koji su u funkciji provere trenutnog nivoa poznavanja materije koja se proučava, a zatim i znanja stečenih tokom cele nedelje koliko traje jedan segment kursa.

- Čitanje ponuđenih materijala koji podrazumevaju stručne i naučne članke, pažljivo odabrane i u skladu sa potrebama svakog nastavnika - polaznik kursa bira tekstove namenjene učenju engleskog na ranom uzrastu, nastavi sa mladima ili odraslima. Ova aktivnost daje polaznicima mogućnost direktnog usmeravanja pravca u kom će da se razvija kurs za svakog nastavnika pojedinačno; „u e-učenju srž obrazovnog procesa je u odnosu učenika i didaktičkog materijala, dok nastavnik funkcioniše kao konsultant" (Andrade 377). Kvizovi su stoga prilagođeni nivoima i sadržajima koje su polaznici odabrali putem ponuđenih materijala.

- Učestvovanje u diskusiji na forumu. Tokom svake nedelje, uz materijal koji je potrebno odabrati i pročitati, otvaraju se i prateće diskusije u skladu sa temom za datu nedelju. Učešće u diskusijama je obavezno, i vrednuje se kvalitet odgovora u smislu da je u vezi sa temom i za nju relevantan. Svaki odgovor daje mogućnost daljeg komentarisanja, pa čak i dodeljivanja „boda” kako bi se naglasilo da ga ostali učesnici smatraju izuzetno korisnim.

- Rad na projektu. Tokom ovog kursa, projekat je podrazumevao sastavljanje dva plana časa, u skladu sa propisanim normama. U određenom vremenskom okviru, plan se predaje na ocenjivanje ostalim polaznicima, da bi na kraju određene nedelje polaznik ocenio kako sopstveni plan, tako i jos nekoliko planova svojih kolega.

- Opcione aktivnosti: ove aktivnosti odnose se na čitanje i komentarisanje dodatnih nastavnih materijala, učestvovanje u igri otkrivanja tajnog predmeta, pokretanju novih diskusionih grupa i sl. Ove aktivnosti ne podležu bodovanju za potrebe dobijanja sertifikata o uspešno savladanom kursu. 
Svaki od ovih zadataka od polaznika iziskuje razvoj kritičke misli u odnosu na sopstveni rad, ali i rad ostalih nastavnika. Neophodna je doza kreativnosti kako bi se svakom zadatku pristupilo na zadovoljavajući način i odgovorilo na tražene aktivnosti. Nije zanemarljiv ni aspekt međusobnog ocenjivanja, koji se kao koncept usvaja tokom kursa i može dalje da se primeni u sopstvenoj učionici.

\subsection{Polaznici MOOK-a kao članovi delatne zajednice}

Pored samostalnog rada, značajan deo aktivnosti polaznika MOOKa predstavlja interakcija među nastavnicima. Pošto je u pitanju grupa polaznika okupljena oko zajedničkog angažovanja, grupa koja deli sličan način komuniciranja, vrednosne stavove, profesionalna usmerenja, možemo govoriti o grupi koja u trenutku okupljanja na kursu čini jednu delatnu zajednicu:

Kao društveni konstrukt, delatna zajednica se razlikuje od tradicionalne zajednice jer je istovremeno definišu njeni članovi, kao i delatnost kojom se ti članovi bave (Eckert, \& McConnell-Ginet 1992:464; cit. u: Holmes \& Meyerhoff 1999: 174) (Filipović 132).

Ovo je važno da primetimo jer upravo članovi date delatne zajednice definišu tok MOOK-a; iako je pravac i sadržaj kursa unapred određen, svaki pojedinac-učesnik kursa doprinosi njegovom usmeravanju i razvoju. Putem komentara ili izvršenih zadataka, polaznici predstavljaju svoj identitet, lično iskustvo, kolektivno iskustvo zemlje/strukovne zajednice kojoj pripadaju, starosnu dob pa samim tim i metodička iskustva koja u nastavi (ne)poseduju, svoju motivaciju i kreativnost, stavove o nastavi ( $i$ ne samo nastavi) itd. Bilo bi veoma interesantno porediti ukupne rezultate identičnog MOOK-a koji bi se sproveo sa različitim polaznicima, ili u različitim vremenskim intervalima. U tom slučaju, okosnica kursa bila bi ista, ali celokupan razgranati sistem koji je sadržaj realizovanog MOOKa verovatno bi se značajno razlikovao. I upravo zato su delatne zajednice "dinamične, bogate i kompleksne" (Holmes and Meyerhoff 174) i doprinose zajedničkom učenju i deljenju znanja. Venger, u ovom smislu, govori o tri krucijalne dimenzije delatnih zajednica: a) zajedničko angažovanje 
b) udruženi pregovarani poduhvat c) repertoar mogućih resursa sakupljenih tokom vremena koji zajednica deli (Holmes and Meyerhoff 175) i možemo utvrditi da su sve tri pomenute dimenzije prisutne tokom realizacije MOOK-a:

a) Zajedničko angažovanje prisutno je, i redovno je - „ono je osnova odnosa koji čini delatnu zajednicu mogućom" (Holmes and Meyerhoff 175). Tokom pet nedelja, komunikacija se neprestano odvija među polaznicima; bez nje nije moguće izvršiti postavljene zadatke, a pri tom je i uslov za uspešno savladavanje kursa. Ogleda se kroz diskusije, rad na projektu, ali i opcione aktivnosti koje su delimično i neformalnog karaktera.

b) Udruženi poduhvat se odnosi na proces koji nije samo težnja ka zajedničkom cilju, već i usputno „pregovaranje” i dogovaranje, samim tim i učenje, čime se postiže pripadnost delatnoj zajednici. Uloga svakog člana zajednice je da doprinese zajedničkom poduhvatu u skladu sa svojim mogućnostima, znanjem i idejama.

c) „Repertoar mogućih resursa sakupljenih tokom vremena koji zajednica deli uključuje lingvističke resurse kao što su specijalizovana terminologija i lingvističke rutine, ali takođe i resurse kao što su slike... ili gestovi koji su postali deo delatne zajednice" (Holmes and Meyerhoff 175). Zajednica nastavnika na MOOK-u takođe deli zajednički repertoar; pre svega, postoji zajednički diskurs koji je umnogome već formiran kod polaznika i pre priključivanja kursu. Prisutni su ustaljeni pozdravi, način obraćanja i diskutovanja koji se možda razlikuje na individualnom planu, ali tokom rada onlajn, svi polaznici usvoje zajednički okvir unutar kog komuniciraju, terminologija je zajednička, a vremenom se jave i interne šale ili saznanja o tome šta može da se „sazna” od kog polaznika.

Pored neospornog proširivanja opsega nastavnih tehnika koje pojedinac poznaje, pristupa novom materijalu i učenju iz iskustava kolega, MOOK je prilika da se nastavnik pozicionira u okviru svoje struke među istomišljenicima; pristup radu, usavršavanju i nastavi razlikuje se kod pojedinačnih polaznika kursa, ali im je zajednička težnja ka napredo- 
vanju. Učestvovanjem u ovom MOOK-u, nastavnik postaje deo zajednice čiji su vrednosni stavovi slični, zajednice koja poštuje i pokazuje da ume da sasluša/pročita mišljenje kolega. Pored stručne i informaciono-komunikacione tehnološke veštine, polaznik se navikava i na jednu specifičnu društvenu sredinu koja se formira onlajn, i unutar koje se pozicionira u odnosu na ostale članove.

\subsection{Upravljanje i organizacija vremena}

Sopstveni razvoj pojedinac bi trebalo da planira i usmerava. Ukoliko želimo da uspešno upravljamo svojim znanjem, trebalo bi da naučimo i da upravljamo vremenom koje imamo i koje je ograničeno. Svesni toga, autori MOOK-a preciziraju trajanje kursa i nude modele rada u cilju uspešnijeg i boljeg krajnjeg rezultata. Ceo kurs podeljen je na pet segmenata, koji se realizuju tokom pet nedelja, koliko kurs i traje. Tokom svake nedelje zadaju se aktivnosti i materijali koji su zasebna celina, te se na taj način i vrednuju. Svi rešeni zadaci predaju se tako što se postavljaju na sajt kursa putem korišćene platforme, u traženim formatima (word document, PDF, itd.)

S obzirom na plan i tok realizacije kursa, rokovi su striktni i očekuje se da ih svi polaznici poštuju. Uzimajući u obzir razlike u vremenskim zonama, jasno su naznačene vremenske zone i ponuđen link koji olakšava „prevođenje” lokalnog vremena u odgovarajući termin kada ističe rok za predaju zadataka. Bilo kakvo odlaganje ili prihvatanje zadataka mimo rokova nije dopušteno. Ovakav način rada, koji se nekima čini kao negativna strana MOOK kurseva zapravo nas uči veštini organizacije vremena. Uprkos tome, veliki broj polaznika odustaje već od samog početka, zbog nedostatka samodiscipline i organizacionih sposobnosti.

Svesni ovog izazova, autori kursa predstavljenog u ovom radu kao dva dodatna alata ponudili su i dve vrste listi: To-do lists i End of week checklists. Prva lista namenjena je polaznicima koji žele da planiraju svoje nedeljne aktivnosti na MOOK-u. Ona se sastoji iz svih obaveznih i opcionih aktivnosti predviđenih za tu nedelju i može se odštampati ili sačuvati na kompjuteru ili drugom uređaju koji koristimo. Takođe, sadrži linkove koji vode do zadataka ili materijala i napomena o bodovanju. Za one kojima je dodatna pomoć pri organizaciji neophodna, ponuđen je i predlog rada za pojedinačne nedelje, sa ravnomerno raspoređenim opterećenjem tokom svakog dana u nedelji. Druga vrsta liste može da posluži i kao dopunska lis- 
ta, jer su na njoj navedene sve predviđene aktivnosti sa praznim prostorom u koji je moguće upisati plus po obavljenoj aktivnosti. Ova lista je zapravo podsetnik šta smo u toku nedelje već uradili, a šta nam je preostalo, tako da ne previdimo neki od zadataka i time izgubimo bodove.

Upravljanje vremenom i organizacija vremena predstavljaju veštine koje su potrebne da bi se MOOK kursevi uspešno završili, te je nemogućnost prilagođavanja ovakvom načinu rada jedan od razloga neprihvatanja ovog vida usavršavanja ili nemogućnosti da se u usavršavanju i istraje: „Većinu MOOK kurseva završi manje od 10\% upisanih polaznika“ (Liyanagunawardena 218).

Živa reč i usmena podrška nastavnika veoma često u nastavnoj praksi predstavljaju prekretnicu u motivaciji i stavu učenika i studenta prema nastavnoj materiji, pa čak i u istrajavanju u školovanju pojedinca. Druženje sa kolegama izvan učionice, a u ovom slučaju virtuelne zajednice, kao i samo iskustvo pohađanja tradicionalne škole ipak ne može da zameni onlajn prostor.

\subsection{Ocenjivanje i pravila ponašanja}

„Upravljanje znanjem uključuje tehnike za identifikaciju i kvantifikaciju nematerijalnih vrednosti u bazi znanja kompanije" (Masulas 2000, cit. u Marković 59). Postojanje znanja i veština, njihovo posedovanje i plasiranje na tržište potrebno je potkrepiti i dokumentovati. Iz tog razloga, potvrda o uloženom trudu i vremenu, kao i o uspešnosti u savladavanju predviđenog materijala ili gradiva potrebna je i po završenom stručnom usavršavanju, u ovom slučaju, kursu. Sa druge strane, dodelom sertifikata kreira se svojevrsna baza podataka o profesionalcima i praktičarima baza nastavnika jezika koji su savladali određeni kurs. Vrednost takvog nastavnika, koji ulaže svoje vreme, trud i resurse da se usavrši i primeni novostečeno znanje predstavlja intelektualni kapital koji podiže konkurentnost ustanove u kojoj je taj nastavnik zaposlen i time se privlače potencijalni saradnici ili učenici/studenti. Sertifikatom polaznik potvrđuje i „vlasništvo znanja”, tj. pravo intelektualne svojine svakog komentara ili urađenog zadatka koji je plasirao onlajn.

Polaznici koji uspeju da savladaju najmanje $70 \%$ ocenjivanih sadržaja tokom kursa, smatra se da su uspešno ispunili postavljene zadatke i da su 
ovladali najvažnijim elementima kursa. Oni dobijaju sertifikat Coursera Statement of Accomplishment kojim se to potvrđuje. Oni polaznici koji ostvare još bolje rezultate, a pod tim se podrazumeva $85 \%$ i više ocenjivanih sadržaja tokom kursa dobijaju sertifikat Coursera Statement of Accomplishment with Distinction. Ovi sertifikati su digitalni dokumenti koji se mogu sačuvati i odštampati. Brojne kompanije i ustanove širom sveta prihvataju MOOK sertifikate kao legitiman vid usavršavanja i potvrdu o stečenim znanjima i veštinama polaznika kurseva.

Tokom petonedeljnog rada, vrednuje se kako individualni rad polaznika, tako i saradnja sa kolegama. Sumativna ocena dobija se na osnovu sledećih elemenata:

1. Postavljanje komentara na diskusionim forumima, pri čemu se kao minimum očekuju dva komentara tokom nedelje. Oni čine $25 \%$ krajnje ocene, odnosno $5 \%$ ocene za svaku nedelju.

2. Rešavanje nedeljnog kviza čini $25 \%$ krajnje ocene, pri čemu se uzima u obzir broj tačnih odgovora.

3. Prva faza projekta podrazumeva sastavljenje početnog plana jednog časa, ocenjivanje radova ostalih polaznika kursa, ali i samoocenjivanje, što ukupno sačinjava $20 \%$ krajnje ocene.

4. Druga faza projekta u kojoj se revidira i proširuje plana časa, ocenjuju radovi ostalih polaznika kursa i ponovo ocenjuje sopstveni rad, što ukupno čini $30 \%$ krajnje ocene.

S obzirom da se kurs odvija u multikulturnoj, multinacionalnoj profesionalnoj sredini, ali ipak virtuelnoj, propisana su pravila onlajn ponašanja u okviru pohađanja kursa. Ona nose naziv "Netiquette", što predstavlja slivenicu imenica "Internet" i "etiquette". U pitanju je skup pravila ponašanja koja podrazumevaju pristojnost u ophođenju, ali i savetuju da se poštuju sledeće preporuke: kako bi se izbegla ponavljanja, a s obzirom na brojnost polaznika, preporučljivo je da se pre postavljanja komentara u diskusijama prvo pročitaju već postavljene ideje i iskazani stavovi. U pozadini ovakve preporuke je nastojanje da se uštedi vreme prilikom pronalaženja odgovarajućih hipoteza, a sa druge strane svest o ograničenosti resursa u pojedinim državama iz kojih mogu biti potencijalni polaznici, u smislu nedostupnosti kompjutera, interneta, slabijih signala mreže, ograničenog vremena za korišćenje interneta i sl. Dalje, preporučuje se da pre postav- 
ljanja poruke na forum razmislimo o njenoj relevantnosti i načinu na koji ona može da se protumači. Svakako treba izbegavati bilo kakvu mogućnost da se neko nađe uvređen ili oseti manje vrednim zbog komentara, pa čak i ako su oni napisani sa dobrom namerom i ako su iskreni. Zatim, skreće se pažnja na vrednost napisane reči u akademskom kontekstu. Jasnoća i lepota izraza, poštovanje interpunkcije, a pre svega, pažnja pri izboru reči i vođenje računa o gramatičkim i drugim jezičkim i stilskim pravilima se podrazumevaju. Kao i u bilo kom drugom pisanom radu, preuzimanje tuđih reči bez navođenja citata smatra se plagijatorstvom i nije prihvatljivo; ono takođe predstavlja i kršenje pravila Coursera kodeksa časti.

\section{Sadržaj i ishodi MOOK-a Shaping the Way We Teach English}

U prethodnom delu rada bilo je reči o organizaciji MOOK-a Paths to Success in English Language Teaching - Shaping the Way We Teach English. Sadržaj ovog MOOK-a, koji se realizuje kao dva zasebna kursa (Shaping the Way We Teach English 1 i Shaping the Way We Teach English 2) predstavljen je po nedeljama i bavi se sledećim temama:

Shaping the Way We Teach English 1:

Nedelja 1: Autentični nastavni materijali

Nedelja 2: Grupni i rad u parovima; komunikativni pristup u nastavi Nedelja 3: Kritičko i kreativno mišljenje

Nedelja 4: Formativno i druge vrste ocenjivanja

Nedelja 5: Jezik u kontekstu.

Shaping the Way We Teach English 2:

Nedelja 1: Integrisane veštine

Nedelja 2: Alternativni vidovi ocenjivanja

Nedelja 3: Individualne razlike kod učenika/studenata

Nedelja 4: Organizacione tehnike u učionici

Nedelja 5: Reflektivna nastava.

Kao što se može zaključiti po nastavnim programima ova dva kursa, obuhvaćeni su najznačajniji metodički i didaktički aspekti nastave en- 
gleskog kao stranog jezika; od izbora nastavnih materijala i načina njihove uspešne upotrebe na času, preko organizacije časa, podsticanja motivacije i kreativnosti, ali i razvoja kritičkog mišljenja kod učenika i studenata, do ocenjivanja i samoevaluacije. Ishodi koje polaznik ova dva MOOK-a po uspešno savladanim kursevima može da očekuje su sledećit: polaznici će biti u stanju da objasne kako različiti nastavni materijali, raznovrsne aktivnosti u nastavi i različiti pristupi olakšavaju učenje jezika; moći će da izaberu odgovarajuće nastavne materijale i primene nove aktivnosti u nastavi; zatim, moći će da unaprede ocenjivanje učenika/studenata, sopstveni rad, kao i rad svojih kolega nastavnika; moći će da analiziraju i prilagode nastavu u skladu sa datom nastavnom situacijom i da sastave svrsishodan, autentičan plan časa. Takođe, polaznici ovih kurseva proširiće opseg svog profesionalnog delovanja, povezaće se sa kolegama širom sveta i podstaći će svoju kreativnost u daljem radu i nastavnom pristupu, dok će istovremeno razvijati veštine upotrebe informaciono-komunikacionih tehnologija.

\section{Implikacije za razvoj novih kurseva - MOOK za srpski jezik?}

„Troškovi tradicionalnog formalnog obrazovanja postaju neodrživi. Mogućnost besplatnog unapređenja znanja na akademskom nivou putem interneta smatra se najvažnijom inovacijom u obrazovanju u poslednjih 200 godina" 5 - poručuju nam na jednom od portala namenjenog mladima. U razvijenim zemljama ovaj stav iznedrio je niz kurseva koji su ponuđeni svima koji su zainteresovani da putem njih prošire svoja znanja. Internet je takođe i nezaobilazni izvor informacija, pogotovo za generacije koje su odrastale uz njega.

U našem okruženju, ovi svetski trendovi sve više dobijaju na snazi: na primer, Univerzitetska biblioteka "Svetozar Marković" iz Beograda promoviše koncept besplatnih kurseva koji su dostupni preko interneta, a

$4 \quad$ Svakako treba uzeti u obzir i prethodno znanje, formalno i neformalno obrazovanje i iskustvo koje pojedinačni polaznici već imaju ili nemaju; individualne razlike među polaznicima ne mogu da se zanemare bez obzira na to što kursevi nisu ograničeni samo na nastavnike sa iskustvom u nastavi. pljeno sajtu 08.01.2016.] 
takođe je i kreirala portal „Znanje za sve” pokrenuvši inicijativu prevođenja besplatnih onlajn edukativnih kurseva na srpski jezik, zahvaljujući Klubu volontera Univerzitetske biblioteke. ${ }^{6}$

Pored prevoda već postojećih kurseva, šta nedostaje našoj obrazovnoj praksi? Šta bi bilo korisno velikom broju studenata, ali i radnika iz najrazličitijih oblasti, pogotovo onima koji se bave pisanom rečju? Uvidom u štampu i druge pisane materijale, programe na televiziji i medije uopšte, kao i svakodnevnu međuljudsku komunikaciju, možemo da zaključimo da učenje i primena gramatike i vokabulara maternjeg jezika ne bi trebalo da se završi izlaskom iz školskih klupa. Srpski jezik i književnost obavezan je predmet u osnovnom i srednjem obrazovanju u Republici Srbiji, i za većinu se ne nastavlja tokom studija ili daljeg stručnog usavršavanja. Kursevi poput MOOK-a mogli bi da ponude atraktivan i aktivan način učenja velikom broju ljudi koji su osetili potrebu da dopune svoje poznavanje pravila pisanja, interpunkcije, upotrebe velikog slova i sl. u srpskom jeziku. Takođe, postoji i interesovanje stranaca da uče naš jezik, tako da bi ponuda mogla dalje da se grana u zavisnosti od predznanja ili potreba polaznika kurseva koji žele da uče srpski jezik. Mlađi naraštaji su pasionirani korisnici društvenih mreža, komuniciraju uglavnom putem mobilnih telefona i drugih uređaja na kojima često nisu instalirana slova naših pisama sa odgovarajućim dijakritičkim znacima, te se i pri njihovom pisanju na papiru primećuje, na primer, nerazlikovanje fonema $c$, ć i č; $z$ i ž; $s$ i š. Često se javlja transfer strukture rečenice iz engleskog jezika, tako da pri pisanju ili govoru na maternjem srpskom jeziku ponekad dolazimo u situaciju da ne razumemo izgovoreno ili napisano. Bogatstvo našeg jezika ogleda se i u upotrebi dva pisma, tako da bi stranci i oni koji imaju potrebu za tim mogli putem odgovajućih zadataka da uvežbaju korišćenje ćirilice i latinice. Pisana i izgovorena reč na akademskom nivou nosi posebnu, obrazovnu težinu te je neophodno da se pridržavamo pravila pisanja i govora i kao studenti i kao predavači, a tome bi mogli da doprinesu npr. MOOK kursevi srpskog jezika za akademske potrebe.

„Upravljanje znanjem, kao aktivnost, zahteva stvaranje projekata u obliku isprobanih i stvarnih alata i tehnika koji su izgrađeni na osnovu opštih prednosti u ekonomiji i u upravljanju znanjem, kao discipli-

6 http://www.unilib.rs/o-nama/projekti/prenos-znanja-sadrzaja-i-programa/ [Pristupljeno sajtu 08.01.2016.] 
ni“ (Marković 59-60). Onlajn kursevi, kao efikasni, ekonomski opravdani, ekološki projekti treba da budu i prilagođeni lokalnim prilikama i uslovima. „Lokalni odgovor podrazumeva da organizacija odgovori zahtevima i osobenostima lokalnog tržišta - na primer, „globalni automobil“ mora da se prilagodi kako bi odgovarao određenim lokalnim uslovima gde se prodaje" (Newell 65). Okvir koji nam daju MOOK programi može da se primeni na brojne sadržaje, tako da će ovaj vid učenja i usavršavanja nuditi svoje pogodnosti u onolikoj meri u kolikoj postoji interesovanje i volja za kreiranje novih tema i kurseva na stranim, ali i na srpskom jeziku.

\section{Zaključak}

Masovni otvoreni onlajn kursevi predstavljaju značajan doprinos obrazovanju i usavršavanju na globalnom nivou. Oni povezuju ljude iz različitih sredina, dinamični su, zahtevaju angažovanje polaznika aktivno učenje, besplatni su, realizuju se bez potrebe za putovanjem ili prilagođavanjem termina za pohađanje nastave, i na posletku, ekološki su jer doprinose očuvanju prirodnih resursa. Pored pogodnosti koje nude ovakvi vidovi učenja, oni zahtevaju od polaznika samoorganizaciju, usmerenost pažnje za koju je neophodna samodisciplina i motivisanost kako bi se ispunili zahtevi kursa, $i$ istrajnost da polaznik kurs ne samo upiše, već $i$ završi. Paralelno sa oblašću koju je polaznik izabrao, usavršavanje se odvija i na nivou upotrebe informaciono-komunikacionih tehnologija. Ne treba zanemariti ni vrednost razmene iskustava, ideja i povezivanja sa kolegama sa različitih meridijana i iz različitih društvenih i obrazovnih sredina.

Kao jedan od načina za usavršavanja nastavnika, pohađanje ovakvih kurseva pruža mogućnost da nastavnik unapredi sopstveni rad, pomogne učenicima/studentima u sličnim aktivnostima, razvije saradnju i komunikaciju u okviru svoje delatne zajednice i pruži podršku kolegama pri sličnim nastojanjima. Tradicionalne vidove nastave koji neosporno imaju svoje prednosti možemo nadograditi dodatnim znanjima i veštinama kao što je usavršavanje putem masovnih otvorenih onlajn kurseva, i nastojati da i u lokalnom kontekstu razvijemo slične programe. 


\section{Literatura}

Andrade, Javier et al. "Knowledge Management as an E-Learning Tool." Knowledge Management: Concepts, Metodologies, Tools, Aplications. Ed. Murray Jennex. New York: Hershey, Information Science Reference, 2008. 376-384.

Filipović, Jelena. Moć reči. Ogledi iz kritičke sociolingvistike. Beograd: Zadužbina Andrejević, 2009.

Filos, Erastos. "Smart Organizations in the Digital Age." Knowledge Management: Concepts, Metodologies, Tools, Aplications. Ed. Murray Jennex. New York: Hershey, Information Science Reference, 2008. 48-72.

Holmes, Janet, and Miriam Meyerhoff. "The Community of Practice: Theories and methodologies in language and gender research." Language in Society 28.2 (1999): 173-183.

King, William R. "Knowlegde Sharing." Knowledge Management: Concepts, Metodologies, Tools, Aplications. Ed. Murray Jennex. New York: Hershey, Information Science Reference, 2008. 73-80.

Liyanagunawardena, R. Tharindu et al. "MOOCs: A systematic study of the published literature 2008-2012." The International Review of Research in Open and Distributed Learning 14.3 (2013): 202-227.

Marković, Ljiljana. Upravljanje znanjem. (udžbenik u izradi)

Nacionalni prosvetni savet Republike Srbije. Smernice za unapređivanje uloge informaciono-komunikacionih tehnologija u obrazovanju. Beograd, 2013.

Newell, Sue et al. "New Organizational Forms That Support Knowledge Work: the Role of ICT." Managing Knowledge. Work and innovation. Second edition. Palgrave Macmillan, 2009. 54-78.

Sivakumar, Shyamala C. "E-Learning for Knowledge Dissemination." Encyclopedia of Knowledge Management. Ed. Schwartz, David. IGI Global, 2006. 152-160.

Wallace, Danny P. Knowledge Management: Historical and cross-disciplinary themes. Libraries Unlimited, 2007.

https://www.coursera.org/course/shaping2paths [Pristupljeno sajtu novembar-decembar 2015.]

http://portalmladi.com/besplatni-kursevi-svetskih-univerziteta-na-srpskom-jeziku [Pristupljeno sajtu 08.01.2016.]

http://www.unilib.rs/o-nama/projekti/prenos-znanja-sadrzaja-i-programa/ [Pristupljeno sajtu 08.01.2016.] 


\title{
Svetlana Velimirac
}

University of Belgrade

Faculty of Philology

\section{DIGITAL AGE AND THE TRAINING OF FOREIGN LANGUAGE TEACHERS}

\begin{abstract}
Summary
Training of foreign language teachers in the digital era implies adjustment to the time in which the teacher is active, most of all to the technologies that surround him, which have become an integral part of everyday working routine. This paper presents an example of English language teachers training through $\mathrm{MOOC}$ - massive open online course: Paths to Success in English Language Teaching - Shaping the Way We Teach English. Advantages and disadvantages of this type of training, as well as a confirmation of forming a community of practice during the teachers' active participation in the MOOC are the core of this paper. Technology is an integral part of distance learning, and in addition to the basic purpose of the course, participants also progress and develop in ICT, which is a necessary skill for every modern teacher today. Exchange of experiences, ideas and connecting with colleagues from different countries, social strata and educational contexts are an additional incentive for accepting this global trend in improving the knowledge and skill of foreign language teachers in our country as well.
\end{abstract}

Key words: E-learning, communities of practice, teachers, training, $\mathrm{MOOC}$ 